\title{
Optimal uptake kinetics: physiological acclimation explains the pattern of nitrate uptake by phytoplankton in the ocean
}

\author{
S. Lan Smith ${ }^{1, *}$, Yasuhiro Yamanaka ${ }^{1,2,3}{ }^{\text {, Markus Pahlow }}{ }^{4}$, Andreas Oschlies ${ }^{4}$ \\ ${ }^{1}$ Ecosystem Change Research Program, Frontier Research Center for Global Change, JAMSTEC, 3173-25 Showa-machi, \\ Kanazawa-ku, Yokohama 236-0001, Japan \\ ${ }^{2}$ Hokkaido University, Sapporo, Japan \\ ${ }^{3}$ Core Research for Evolutional Science and Technology (CREST), Japan Science and Technology Agency (JST), \\ Sanbancho 5, Tokyo 102-0075 \\ ${ }^{4}$ Leibniz Institute of Marine Sciences at Kiel University (IFM-GEOMAR), Kiel, Germany
}

\begin{abstract}
Phytoplankton supply the base of the marine food web and drive the biogeochemical cycles of carbon and nutrients. Over much of the ocean, their growth is limited by their uptake of nitrogen (as nitrate), which has most commonly been described by the hyperbolic Michaelis-Menten (MM) equation. However, the lack of a theory to explain variations in MM constants has hindered our ability to predict the response of marine ecosystems to changes in environmental conditions. The MM equation fits data from short-term experiments well, but does not agree with steady-state experiments over wide ranges of nutrient concentrations. In contrast, the recently developed optimal uptake kinetics (OU) does agree with the latter and can also describe the observed pattern of MM halfsaturation constants from field experiments. OU kinetics explains the observed pattern of $\mathrm{N}$ uptake as the result of a general physiological trade-off between nutrient uptake capacity and affinity. The existence of a general trade-off would imply a relatively high degree of predictability in the response of nutrient uptake to changing nutrient concentrations and thus provide a basis for predicting effects of climate change on marine ecosystems and biogeochemical cycles.
\end{abstract}

KEY WORDS: Nutrient uptake $\cdot$ Kinetics $\cdot$ Phytoplankton · Nitrogen · Nitrate · Biogeochemical model

Resale or republication not permitted without written consent of the publisher

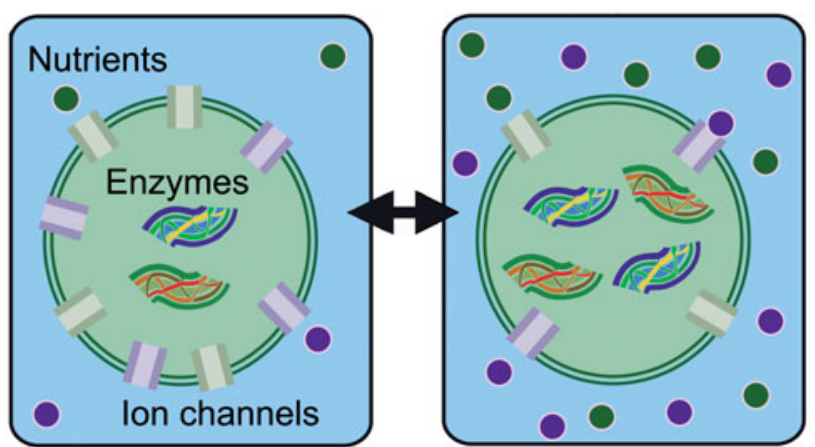

Phytoplankton cells acclimate to low (left) versus high (right) nutrient concentrations, modifying their apparent half-saturation constants for nutrient uptake.

Diagram: S. L. Smith

\section{INTRODUCTION}

Over most of the ocean, the growth of phytoplankton near the surface is often limited by nitrogen, much of which is supplied as nitrate by upwelling of deep ocean waters (Dugdale 1967, Dugdale \& Goering 1967), although ammonium can be more important in oligotrophic regions. Growth rates are actually limited by intracellular concentrations of nutrients (Caperon 1968, Droop 1968), which are determined largely by their uptake rates from the ambient water (Klausmeier et al. 2004). An under- 
standing of what determines these uptake rates, and hence phytoplankton growth rates, is vital to understand and predict the response of marine ecosystems and biogeochemical cycles to changes in ocean circulation and nutrient supply that result from climate change (Polovina et al. 2008) or direct anthropogenic inputs of N (Duce et al. 2008). Given that, even when embedded in high-resolution physical models, largescale marine ecosystem models cannot reproduce the observed contrast in phytoplankton biomass and production between nutrient-rich and nutrient-poor regions (Oschlies et al. 2000, Gruber et al. 2006), there is reason to seek improved biological models for phytoplankton.

By far the most commonly applied equation to describe uptake rates of nutrients as a function of their ambient concentrations is the Michaelis-Menten (MM) equation:

$$
V_{\mathrm{MM}}=\frac{V_{\mathrm{max}, \mathrm{S}} S}{K_{\mathrm{s}}+S}
$$

where $v_{\mathrm{MM}}$ is the uptake rate for a nutrient with the concentration $S, V_{\text {max }, S}$ is the maximum uptake rate for the nutrient, and $K_{\mathrm{s}}$ is the half-saturation constant (Dugdale 1967). Values for the 2 parameters $V_{\max , s}$ and $K_{\mathrm{s}}$ are fit to experimental data. Although this equation is rigorously correct for chemical reactions governed by a single enzyme, its application to nutrient uptake by phytoplankton is not theoretically justified (Dugdale 1967, Morel 1987). The MM equation, with the constant $K_{\mathrm{s}}$ and with $V_{\max }$ failed to describe the steady-state uptake response over wide ranges of concentrations for both N (Rhee 1974, Gotham \& Rhee, 1981a) and P (Droop 1974, Rhee 1974, Gotham \& Rhee 1981b) as the limiting nutrient in separate experiments with several different species. This called into question whether the MM equation is an adequate description of nutrient uptake by phytoplankton. An alternative equation to calculate nutrient uptake rates independently of the MM equation was derived by (Aksnes \& Egge 1991). Instead of assuming a half-saturation constant for each nutrient, this model defines the affinity, $A_{s !}$ and the maximum uptake rate, $V_{\text {max,s, }}$ in terms of basic cellular physiology (e.g. number of uptake sites on the surface, surface area per site, clearance rate). The affinity-based uptake rate, $V_{\text {aff }}$, is then:

$$
V_{\text {aff }}=\frac{V_{\text {max }, s S}}{\frac{V_{\text {max }, \mathrm{s}}}{A_{s}}+S}
$$

Under the assumption that $A_{s}$ and $V_{\max , s}$ are constants, this equation is equivalent to the MM equation with $K_{\mathrm{s}}=V_{\text {max }, s} / A_{s}$, but in affinity-based kinetics the affinity and maximum uptake rate are assumed to vary with cellular physiology. Over 25 yr ago, Healey (1980) suggested that, in terms of MM kinetics, the ratio $V_{\max } / K_{\mathrm{s}}$ (which roughly approximates $A_{s}$ here), is a better indicator of nutrient uptake efficiency than $K_{\mathrm{s}}$. Aksnes \& Egge (1991) also argued that, compared to $K_{\mathrm{s}}$ values of $A_{s}$ should provide a better measure of the relative ability of various species to compete for nutrients.

\section{Optimal uptake: acclimation}

Optimal uptake (OU) kinetics assumes a physiological trade-off between the efficiency of nutrient encounter at the cell surface $\left(A_{s}\right)$ and the maximum rate at which a nutrient can be assimilated $\left(V_{\text {max }_{1}}\right)$. The key idea is that phytoplankton alter the number of their surface uptake sites (or ion channels), which determine the nutrient encounter time scale, versus internal enzymes, which assimilate the nutrients once encountered. $\mathrm{N}$ was assumed to be the key resource being allocated between these 2 uses, because both the uptake sites and enzymes consist mostly of proteins and therefore require significant amounts of $\mathrm{N}$ (Pahlow 2005). However, the key is not the assumption that the resource being allocated is $\mathrm{N}$, but rather that there is a physiological trade-off between the affinity for nutrients at the cell surface and the maximum rate at which nutrients can be assimilated.

Thus, OU kinetics assumes that a phytoplankton cell dynamically allocates some portion of its internal $\mathrm{N}$ between surface uptake sites and internal enzymes. The fraction of this pool of $\mathrm{N}$ that is allocated to surface sites is denoted $f_{A}$ and the remainder $\left(1-f_{A}\right)$ is assumed to be allocated to internal enzymes, such that $A_{s}=f_{A} A_{0, s}$ and $V_{\text {max }, s}=\left(1-f_{A}\right) V_{0, s}$, where $A_{0, s}$ and $V_{0, s}$ are the potential maximum values of affinity and maximum uptake rate, respectively, for nutrient $s$ (Smith \& Yamanaka 2007 for a complete derivation). These values are defined in terms of the maximum potential number of uptake sites and internal enzymes, and mass transfer rates (Smith \& Yamanaka 2007). They are not necessarily assumed to be constants, although there has been good agreement of this assumption with data from several laboratory experiments covering wide ranges of nutrient concentrations in which phytoplankton were limited by N, P and Vitamin B12 (Pahlow 2005, Smith \& Yamanaka 2007). In an extension of Aksnes \& Egge (1991), the following equation (Pahlow 2005) then describes uptake of the nutrient $s$ :

$$
v_{\mathrm{OU}}=\frac{1}{\left(f_{A} A_{0, s} S\right)^{-1}+\left[\left(1-f_{A}\right) V_{0, s}\right]^{-1}}
$$

The optimal allocation that maximizes uptake rate for a given concentration, $S$, is then: 


$$
f_{A}=\frac{1}{1+\sqrt{\frac{A_{0, s} S}{V_{0, s}}}}
$$

Under the assumption that acclimation is instantaneous, substituting Eq. (4) into Eq. (3) yields:

$$
V_{\mathrm{OU}}=\frac{V_{0, s} S}{\left(\frac{V_{0, s}}{A_{0, s}}+2 \sqrt{\frac{V_{0, s} S}{A_{0, s}}}+S\right)}
$$

which is simply a re-arrangement of the singlenutrient OU equation Eq. (A2) of Pahlow (2005), with the denominator expanded (however, note that there was a typesetting error in the denominators of both Eqs. (14) \& (15) of Smith \& Yamanaka 2007).

This yields specific predictions about how affinity and maximum uptake rate should depend on nutrient concentration. Assuming instantaneous acclimation of phytoplankton to any changes in ambient nutrient concentrations, the OU equation is equivalent to an $\mathrm{MM}$ equation with an apparent half-saturation 'constant' that varies with $S$ :

$$
K_{\mathrm{s}}^{\mathrm{app}}=\frac{V_{0, s}}{A_{0, s}}+2 \sqrt{\frac{V_{0, s} S}{A_{0, s}}}
$$

OU kinetics models the rate of nutrient uptake as equivalent to the rate of nutrient assimilation, which is the rate of incorporation into the organic molecules that constitute biomass (Pahlow 2005). Therefore, it does not describe rapid uptake over short periods of time ('surge uptake') during which uptake exceeds assimilation, which has been observed over timescales of seconds to minutes (Raimbault \& Gentilhomme 1990, Dortch et al. 1991) and even hours (Pedersen 1994). In the terminology of Pedersen (1994), OU kinetics describes 'internally controlled' and 'externally controlled' uptake. Assuming constant values for $V_{0, s}$ and $A_{0, s}$ as in Smith \& Yamanaka (2007) and the present study, is equivalent to assuming that uptake rates are not affected by the nutrient content of the cell, which is consistent with the results of Pedersen (1994).

In the present study, we examine an alternative to the assumption of instantaneous acclimation, namely that the rate of acclimation is slow relative to the timescale of typical nutrient uptake experiments. We then test specific predictions of OU kinetics against observed trends in the MM half-saturation constant for nitrate uptake, $K_{\mathrm{NO}_{3}}$. Finally, we illustrate the effect of switching to OU kinetics in a global biogeochemical climate model.

\section{METHODS}

Short-term approximation. For comparison with half-saturation constants fit to the Michaelis-Menten equation, if the duration of the experiments to determine $K_{\mathrm{s}}$ is short enough, the fitted values of $K_{\mathrm{s}}$ would not be expected to follow Eq. (6), which was derived assuming that phytoplankton can acclimate immediately to ambient nutrient concentration. This assumption may be reasonable for the surface ocean, but is inappropriate for experiments shorter than the time needed for acclimation by phytoplankton. In typical field experiments to measure uptake kinetics, seawater is sampled, nutrients are added to it in various concentrations, the samples are incubated for a few hours, and nutrient uptake is measured at the end of the incubations. If phytoplankton have enough time to acclimate during the experiments, their response should follow Eqs. (5) \& (6).

If the duration of the incubation experiment is shorter than the time required for physiological acclimation, the behavior of the equation is better analyzed by a short-term approximation. The OU equation can be re-written:

$$
v_{\mathrm{OU}}=\frac{\left(1-f_{A}\right) V_{0, s} S}{\left(\frac{\left(1-f_{A}\right) V_{0, s}}{f_{A} A_{0, s}}+S\right)}
$$

which is equivalent to a MM equation with $V_{\max , S}^{\mathrm{app}}=$ $\left(1-f_{A}\right) V_{0, s}$ and $K_{\mathrm{s}}^{\mathrm{app}}=\left[\left(1-f_{A}\right) / f_{A}\right] V_{0, s} / A_{0, s}$. The internal allocation of $\mathrm{N}$ to uptake hardware, $f_{A}$, is determined by physiological acclimation via Eq. (4). If the time scale for acclimation is much shorter than the duration of the incubation experiments, $f_{A}$ depends on the same concentration, $S$, appearing in Eq. (7), which changes with the nutrient additions used in the incubation experiments. This is how Eqs. (5) \& (6) were derived.

On the other hand, if the time scale for acclimation is much longer than the duration of the experiments, $f_{A}$ will remain fixed at its value based on the ambient concentration in seawater, $S_{a}$, to which the phytoplankton were presumably acclimated before sampling. In this latter case, substituting $f_{A}$ (Eq. 4) yields a short-term approximation for $K_{\mathrm{s}}^{\text {app }}$

$$
K_{\mathrm{s}}^{\mathrm{app}}=\sqrt{\frac{V_{0, s} S_{\mathrm{a}}}{A_{0, s}}}
$$

and for $V_{\text {max }, s}$ :

$$
V_{\max , s}^{\mathrm{app}}=\frac{V_{0, s}}{1+\sqrt{\frac{V_{0, s}}{A_{0, s} S_{\mathrm{a}}}}}
$$

Predictions of optimal uptake kinetics. This shortterm approximation predicts that, over timescales shorter than the time required for acclimation, experiments would measure behavior consistent with constant values of $K_{\mathrm{s}}$ and $V_{\text {max,s }}$ because the phytoplankton would be acclimated to the ambient nutrient concentration before sampling, $S_{\mathrm{a}}$ and would not have 
time to acclimate to the nutrient additions used in the incubation experiments. Both the short-term approximation (Eq. 8) and the assumption of instantaneous acclimation (Eq. 6) agree qualitatively with increases in the half-saturation constant for nitrate uptake, $K_{\mathrm{NO}_{3}}$, with nitrate supply, as observed in laboratory experiments on cultures of a single species (Collos 1980). Furthermore, the short-term approximation (Eqs. 8 \& 9) is qualitatively consistent with the positive correlation between maximum uptake rate (per cell) and halfsaturation constant for nitrate uptake in a compilation of data for various species representing major functional types (Litchman et al. 2007). These predictions result from the physiological trade-off between affinity and maximum uptake rate.

Based on a compilation of data from 35 studies in marine waters and assuming MM kinetics, Collos et al. (2005) found the following relationship between $K_{\mathrm{NO}_{3}}$ and $\left[\mathrm{NO}_{3}\right]$ :

$$
K_{\mathrm{NO}_{3}}=a\left[\mathrm{NO}_{3}\right]^{b}
$$

with a value of $b=0.62$. Eq. (10) becomes identical to Eq. (8) if we make the following substitutions: $K_{\mathrm{NO}_{3}}=$ $K_{\mathrm{s}}^{\mathrm{app}}$ and $\left[\mathrm{NO}_{3}\right]=S_{\mathrm{a}}$

$$
a=\sqrt{\frac{V_{0, \mathrm{NO}_{3}}}{A_{0, \mathrm{NO}_{3}}}}
$$

and $b=0.5$. The same substitutions, with the further assumption of instantaneous acclimation, can also be applied to Eq. (6), which deviates from Eq. (10) by predicting a minimum value of $K_{\mathrm{NO}_{3}}$ as $\left[\mathrm{NO}_{3}\right.$ ] approaches zero.

Here, we compare quantitatively the predictions of OU kinetics with observed trends in published values of $K_{\mathrm{NO}_{3}}$. We then present an alternative interpretation for the observed variations in $K_{\mathrm{NO}_{3}}$ in terms of OU kinetics. We focus mostly on variations in the halfsaturation constant for nitrate uptake, $K_{\mathrm{NO}_{3}}$, because patterns in its variation are easier to identify than for $V_{\text {max }}$ (Collos et al. 2005).

Data. We analyzed data for $K_{\mathrm{NO}_{3}}$, determined by fitting the Michaelis-Menten equation to published data from experiments conducted on oceanic observation cruises. First, we further analyzed a compilation of data from 35 studies for which a linear relationship between $\log K_{\mathrm{NO}_{3}}$ and $\log \left[\mathrm{NO}_{3}\right]$ was previously found (Collos et al. 2005). However, the studies spanned a period of over $30 \mathrm{yr}$ and used differing methodologies to determine $K_{\mathrm{NO}_{3}}$, which can yield different results (Harrison et al. 1989). Furthermore, only selected data from the original studies were included in this compilation, with an apparent bias towards selecting high values of $K_{\mathrm{NO}_{3}}$. For example, the greatest value in the compilation was the only one selected from several presented by Shiomoto et al. (1994), even though the validity of that particular value was specifically questioned by
Shiomoto et al. (1994). One could therefore question whether the relationship presented by Collos et al. (2005) truly represents the response of phytoplankton to nitrate concentrations in the ocean.

We therefore conducted an independent test of this relationship, using data from studies that used comparable, modern methodologies, consisting of graded nutrient additions and incubation times from 2 to $3 \mathrm{~h}$ (Harrison et al. 1989). For this, we combined the data from 2 oceanic cruises: one in the North Atlantic Ocean (Harrison et al. (1996); $\mathrm{n}=53$ data points), and one in the Arabian Sea (McCarthy et al. (1999); $\mathrm{n}=8$ data points).

We did not analyze data for $V_{\max }$, because its variations depend on whether it is expressed per cell or per unit biomass (Collos et al. 2005, Litchman et al. 2007), and because it is subject to several sources of variability which would complicate such an analysis. Stronger dependence on temperature is expected for $V_{\max }$ than for $K_{\mathrm{s}}$ (Aksnes \& Egge 1991). Growth rates increase with temperature (Eppley 1972, Goldman \& Carpenter 1974), maximum uptake rates from field experiments are positively correlated with temperature (Kanda et al. 1985), and observed decreases in $V_{\max }$ at high nutrient concentrations (low temperatures) are likely the result of temperature dependence (Harrison et al. 1996). Furthermore, at low nitrate concentrations, uptake rates of nitrate are often reduced in the presence of ammonium (Armstrong 1999).

Analyses. The linear relationship previously found (Collos et al. 2005) between $\log \left(K_{\mathrm{NO}_{3}}\right)$ and $\log \left[\mathrm{NO}_{3}\right]$ was tested by fitting linear regression models to the data. ANOVA tests were used to compare the fit of the general linear model, $\log \left(K_{\mathrm{NO}_{3}}\right)=a+b \log \left[\mathrm{NO}_{3}\right]$, where $a$ and $b$ were determined by the regressions, to the model with $b=0.5$, which is the relationship predicted by OU kinetics. All regressions and statistical tests were conducted using SPlus software (V. 5).

We also fit the corresponding nonlinear regressions, $K_{\mathrm{NO}_{3}}=a\left[\mathrm{NO}_{3}\right]^{b}$, to the data for comparison. The nonlinear and linear fits yielded different values for $a$ and $b$ (results not shown), because of the difference between assuming constant variance (equal weights) for the data in linear or log-log space: the assumption of constant variance gives relatively more weight to larger values in the nonlinear fit, compared to the linear $(\log -\log )$ fit. The residuals from such regressions should ideally be normally distributed, which we tested by comparing plots of the quantiles of the residuals versus the quantiles of the standard normal distribution (Faraway 2005). The residuals were not normally distributed for the nonlinear fits to the untransformed data, but they were nearly normally distributed for the $\log -\log$ fits (results not shown). Therefore, the assumption of constant variance (equal weights) for all data in the nonlinear regression was not valid, 
whereas in the log-log fits, the assumption of constant variance was good. We therefore based our analyses on the log-log regressions.

Global model. The University of Victoria Earth System Climate Model (UVic-ESCM) is a model of global climate, ocean circulation, ecosystems, and biogeochemical cycling, including a fully coupled carbon cycle (Schmittner et al. 2008). Its oceanic ecosystem component includes 2 phytoplankton classes ( $\mathrm{N}$-fixers and other phytoplankton), and nitrate and phosphate as nutrients. A constant chemical composition is assumed for all phytoplankton, and phytoplankton growth is modeled using Michealis-Menten (MM) kinetics (Monod growth kinetics), such that the Cbased growth rate is simply a constant (the C:nutrient ratio of biomass) $\times$ the uptake rate of the growth-limiting nutrient. With this assumption, which is widely applied in large-scale ecosystem models, the growthnutrient curves ( ) have the same shape as the uptakenutrient curves defined by the nutrient uptake kinetics. We implemented a new version of the UVicESCM's marine ecosystem model component by replacing the MM kinetics by OU kinetics, applying the optimality criterion of Smith \& Yamanaka (2007) to extend OU kinetics for multiple nutrients (details are given in Appendix 1).

To illustrate the impact of the proposed switch from MM to OU kinetics, we ran a standard global warming emissions scenario (Schmittner et al. 2008). The model was spun up for several thousand years under constant pre-industrial levels using MM kinetics. For the period 1765-2100 A.D., a control run continued to employ MM kinetics, whereas the OU run used the same initial state (A.D. 1765) and same emission scenario. Parameters for the MM kinetics were $V_{\max }=0.13 \mathrm{~d}$ and $K_{\mathrm{NO}_{3}}=0.7 \mu \mathrm{mol} \mathrm{l}^{-1}$; parameters of the OU kinetics were $V_{0}=1.09, V_{\max }$ and $V_{0, \mathrm{NO}_{3}} / A_{0, \mathrm{NO}_{3}}=0.19$ ( ), giving identical nutrient uptake rates for $\mathrm{MM}$ and $\mathrm{OU}$ at ambient nitrate concentrations of $0.7 \mu \mathrm{mol} \mathrm{l}^{-1}$ (Appendix 1). Both $V_{\max }$ and $V_{0}$ were multiplied with the same temperature function in the UVic model Schmittner et al. (2008).

\section{RESULTS}

The relationship between $K_{\mathrm{NO}_{3}}$ and $\left[\mathrm{NO}_{3}\right]$ is statistically significant $\left(\mathrm{p}<10^{-9}\right)$ for both the data compilation of Collos et al. (2005) ( ) and our independent compilation of data from Harrison et al. (1996) and McCarthy et al. (1999) ( ). The values of the exponent, $b$, are statistically identical $(\alpha=0.1)$, and over half the variance in $K_{\mathrm{NO}_{3}}$ can be explained by its dependence on nitrate concentration $\left(r^{2}=0.56\right.$ and 0.55 for the fits in , respectively). Collos et al. (2005) reported a similar relation-
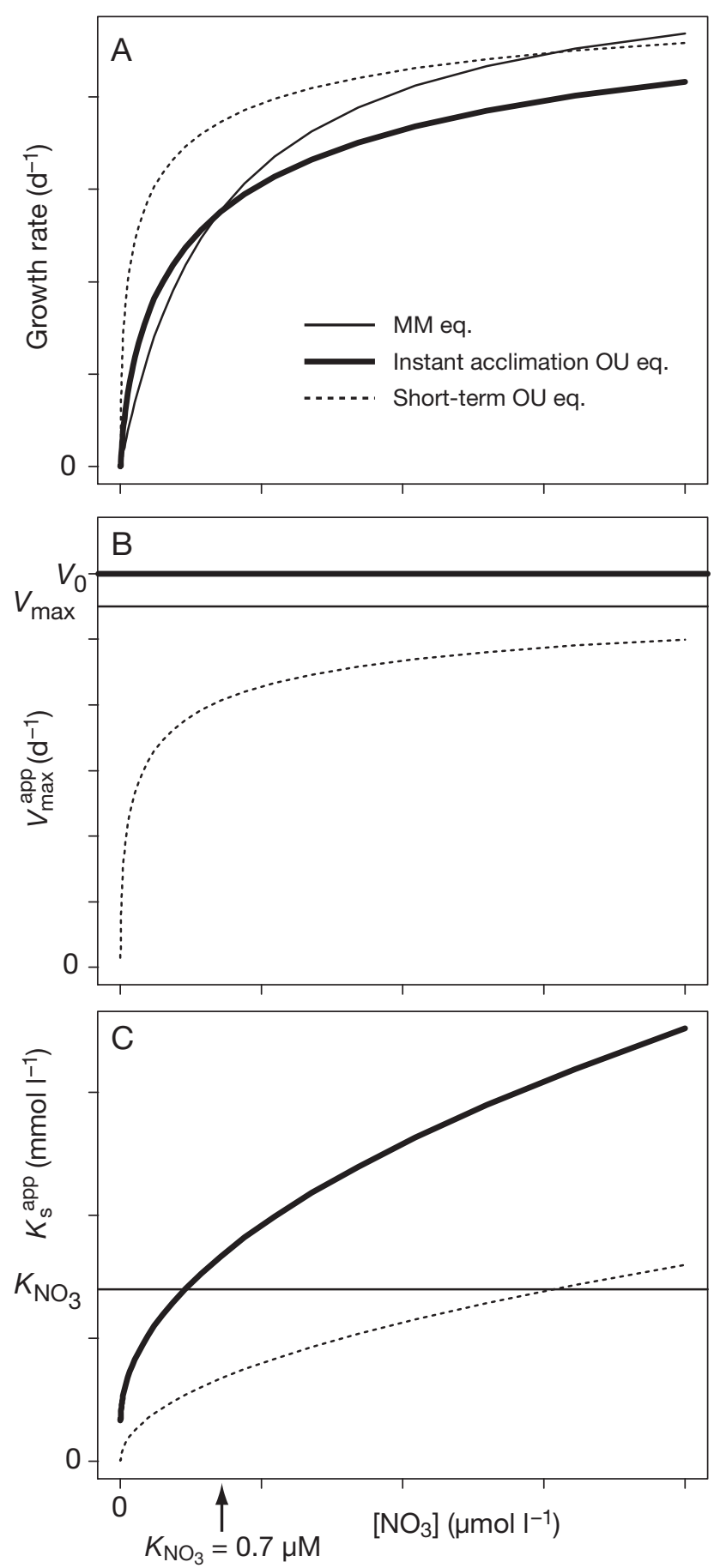

Fig. 1. Behavior of Michaelis-Menten (MM, - $)$ and optimal uptake $(\mathrm{OU},-$ ) kinetics, and the short-term approximation of OU kinetics (------) as a function of nutrient concentration, $S$. Growth rate and maximum growth rate were calculated assuming fixed stoichiometry. (A) Growth rate: accounting for only the variations in $K_{\mathrm{s}}^{\text {app }}$ via the short-term approximation (Eq. 8) with fixed $V_{\max }$ would over-estimate uptake rates (------). (B) Maximum growth rate $\left(V_{\max }^{\mathrm{app}}\right)$ and (C) apparent half-saturation constant $\left(K_{\mathrm{s}}^{\mathrm{app}}\right)$. For OU, $V_{0} / A_{0}$ was taken from and Eq. (11), and $V_{0}$ was set so that the OU equation yields the same rate as the $M M$ equation at $S=K_{\mathrm{NO}_{3}}$ 

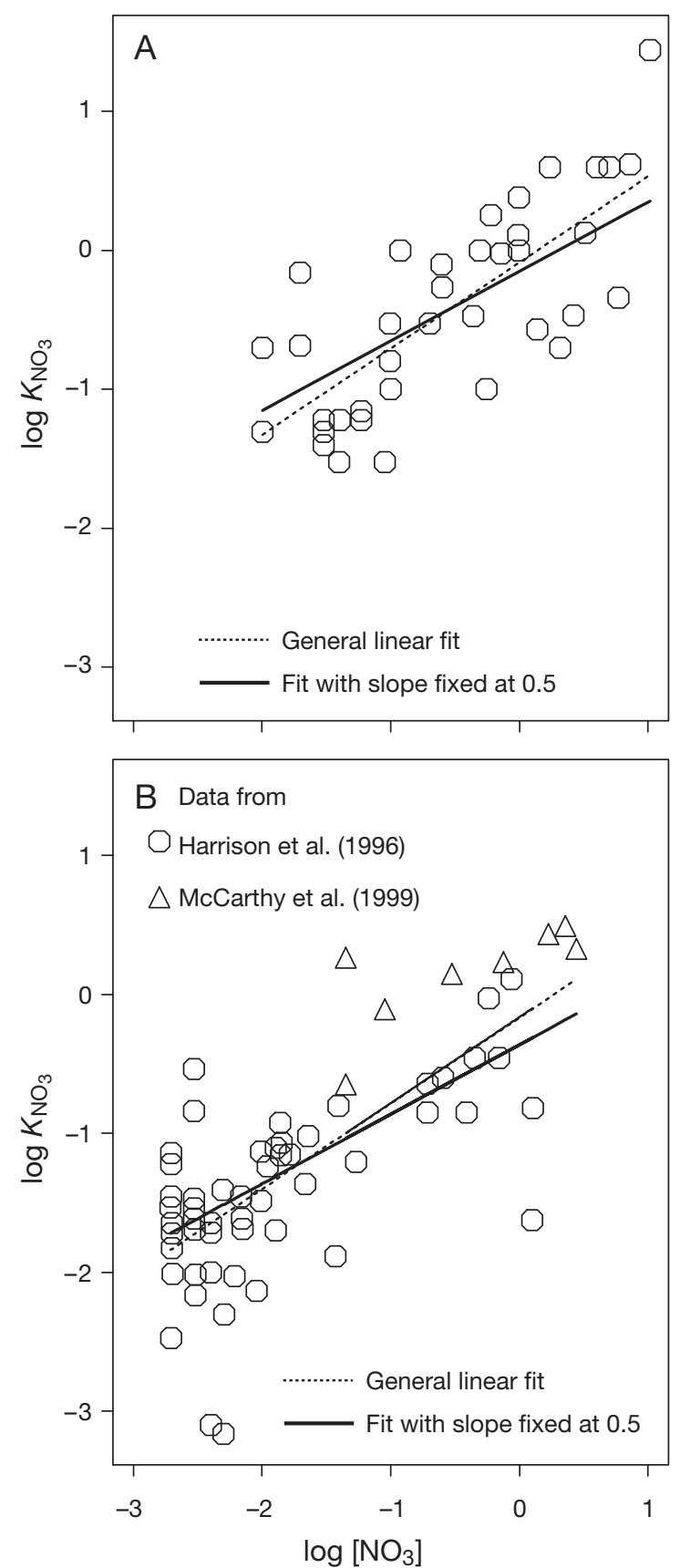

Fig. 2. Observed relationship between $K_{\mathrm{NO}_{3}}$ and $\left[\mathrm{NO}_{3}\right]$ (both in $\mu \mathrm{mol} \mathrm{N} \mathrm{l^{-1 }}$ ), with fits from linear regressions of log-transformed data: $\log K_{\mathrm{s}}=\log a+b \log \left[\mathrm{NO}_{3}\right]$. (A) Oceanic data compiled by Collos et al. (2005). (------) (general equation): $\log a=-0.0881$ $[ \pm 0.0939], b=0.620[ \pm 0.0926]\left(\mathrm{r}^{2}=0.56, \mathrm{n}=37, F=44.8, \mathrm{p}<\right.$ $\left.10^{-9}\right)$. ( $\longrightarrow$ ) (based on OU kinetics): $\log a=-0.152[ \pm 0.0805]$, $b=0.5\left(\mathrm{r}^{2}=0.54, \mathrm{n}=37, t=-1.89, \mathrm{p}<0.066\right)$. Values in brackets are standard errors of fitted parameters. The fitted value of $b=$ 0.620 is not significantly different from 0.5 (ANOVA: $F=1.68$, $\mathrm{p}<0.203$ ). (B) Combined data of (O) Harrison et al. (1996) and $(\triangle)$ McCarthy et al. (1999). (------): $\log a=-0.167$ [ \pm 0.143$], b=$ $0.617[ \pm 0.0738]\left(\mathrm{r}^{2}=0.54, \mathrm{n}=61, F=69.9, \mathrm{p}<10^{-10}\right)$. $(\square)$ : $\log a=-0.364[ \pm 0.0721], b=0.5\left(\mathrm{r}^{2}=0.52, \mathrm{n}=61, t=-5.04, \mathrm{p}<\right.$ $10^{-5}$ ). The fitted value of $b=0.617$ is not significantly different from 0.5 (ANOVA: $F=2.51, \mathrm{p}<0.119$ ) ship ( $\left.b=0.66, \mathrm{r}^{2}=0.51\right)$ for a compilation of data from freshwater studies.

These values of $K_{\mathrm{NO}_{3}}$ were determined by fitting the MM equation to data from experiments conducted during oceanic cruises, using the natural assemblages of phytoplankton present in seawater, and this half-saturation 'constant' depends on the ambient nitrate concentration consistently across wide areas of the ocean. The traditional interpretation in terms of MM kinetics is that these variations reflect intrinsic differences between the species that dominate in different environments (Eppley et al. 1969, Parsons et al. 1984, Litchman et al. 2007). Values of $K_{\mathrm{NO}_{3}}$ do tend to increase with cell size (Eppley et al. 1969) and with cell volume (Litchman et al. 2007). Coupled with an increase in cell size of dominant species as a function of concentration, this could conceivably produce the observed relationship between $K_{\mathrm{NO}_{3}}$ and nitrate concentration.

However, this is not a sufficient explanation for the observed pattern, because $K_{\mathrm{NO}_{3}}$ is not an intrinsic property of each species. Even for single species cultured under controlled conditions, $K_{\mathrm{NO}_{3}}$ increases with nutrient concentration (Collos 1980). For both of the linear regressions of the data ( ), the values of $b$ were not significantly different from $0.5(\alpha=0.1)$, the value predicted by OU kinetics. Fits of the simpler linear model with $b=0.5$ were nearly as good as those of the more general fits and explained just over half of the variance in $\log K_{\mathrm{NO}_{3}}\left(\mathrm{r}^{2}=0.54\right.$ and 0.52 for the data in , respectively). For separate fits (not shown) to the data of Harrison et al. (1996) and those of McCarthy et al. (1999), the slopes were similar (and neither was significantly different from 0.5), but the intercept was greater for the former, $\log a=0.29(0.11)$ than for the latter, $\log a=-0.53(0.17)$.

The data are consistent with the short-term approximation for $K_{\mathrm{NO}_{3}}^{\text {app }}$ (Eq. 8), and the ratio $V_{0, \mathrm{NO}_{3}} / A_{0, \mathrm{NO}_{3}}$ can be estimated from fitting this equation to the observations ( ). From the fitted values of the intercept in the $\log$-log regressions, the estimates of $V_{0, \mathrm{NO}_{3}} / A_{0, \mathrm{NO}_{3}}$ are

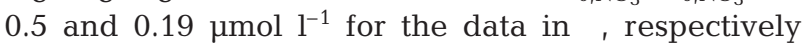
(based on fits with $b=0.5$ ). The assumption of immediate acclimation (Eq. 6) predicts a minimum value for $K_{\mathrm{NO}_{3},}^{\mathrm{app}} K_{\mathrm{NO}_{3}, \mathrm{~min}}^{\mathrm{app}}=V_{0, \mathrm{NO}_{3}} / A_{0, \mathrm{NO}_{3}}$. Fitting Eq. (6), rather than the short-term approximation as above, results in lower values for $V_{0, \mathrm{NO}_{3}} / A_{0, \mathrm{NO}_{3}}$, but with significantly worse fits to the data (see 'Numerical experiments', below). Both datasets contain many values below their respective estimated minima (even the lower minima obtained by fitting Eq. 6); i.e. the data are consistent with the short-term approximation of Eq. (8), but not with Eq. (6). This result for 2 independent compilations of data strongly suggests that OU kinetics is the correct description of uptake and that the acclimation timescale is greater than the duration of the incuba- 
tions used to determine $K_{\mathrm{NO}_{3}}$ (2 to $3 \mathrm{~h}$ for the data in Harrison et al. 1996, McCarthy et al. 1999).

\section{Numerical experiments}

We conducted idealized numerical simulations of the experiments to determine $K_{\mathrm{NO}_{3}}$ as described by Harrison et al. (1996) by assuming values for OU parameters, generating simulated 'data' by sampling this response-assuming that the OU equation was correct and that the phytoplankton were acclimated to the ambient nutrient concentration-and then fitting values of MM parameters to this data for an experiment conducted at each value of ambient nutrient concentration considered. Under the assumption that no acclimation occurred in response to the nutrient additions during the experiments, the generated values of $K_{\mathrm{NO}_{3}}$ recovered the linear $\log -\log$ relationship with $b=0.5$ ( ). Under the assumption that phytoplankton acclimated instantaneously during the experiments, the generated values of $K_{\mathrm{NO}_{3}}$ approached a minimum of $0.016 \mu \mathrm{mol} \mathrm{l^{-1 }}$ at low ambient nutrient concentrations, consistent with Eq. (6) for the long-term value of $K_{\mathrm{s}}^{\mathrm{app}}$. The best-fit of the general $\log$-linear equation $\left(\log K_{\mathrm{s}}=\right.$ $\left.\log a+b \log \left[\mathrm{NO}_{3}\right]\right)$ was significantly better than that of the equation for $K_{\mathrm{s}}^{\text {app }}$, assuming instantaneous acclimation ( ) (ANOVA: $F=10.9, \mathrm{p}<0.0016$ ). The same was true for the data of Collos et al. (2005) displayed in (ANOVA: $F=5.17, \mathrm{p}<0.029$ ).

\section{Temperature}

Temperature may have a confounding effect on uptake response. Near the surface of the ocean, nitrate concentrations are negatively correlated with temperature, because most nitrate is supplied by upwelling of colder water from below. In controlled laboratory studies using single-species cultures, values of halfsaturation constants for N, P and Si uptake for several species have been found to increase with temperature (Eppley et al. 1969, Dauta 1982). The observed correlation of $K_{\mathrm{NO}_{3}}$ with nitrate concentration might therefore result partly from some temperature dependence.

We found only one dataset (Kanda et al. 1985) that reported corresponding values of ambient temperature for each value of $K_{\mathrm{NO}_{3}}$ from field experiments in the North Pacific. For this dataset, the correlation of log$K_{\mathrm{NO}_{3}}$ with $1 / T$ ( $T$ in Kelvin) was slightly weaker than that with $\left[\mathrm{NO}_{3}\right]$ ( ), and each correlation was statistically significant $(\alpha=0.1)$-we compared the correlation with $1 / T$, because that with $T$ was even weaker. There was a significant $(\alpha=0.1)$ correlation

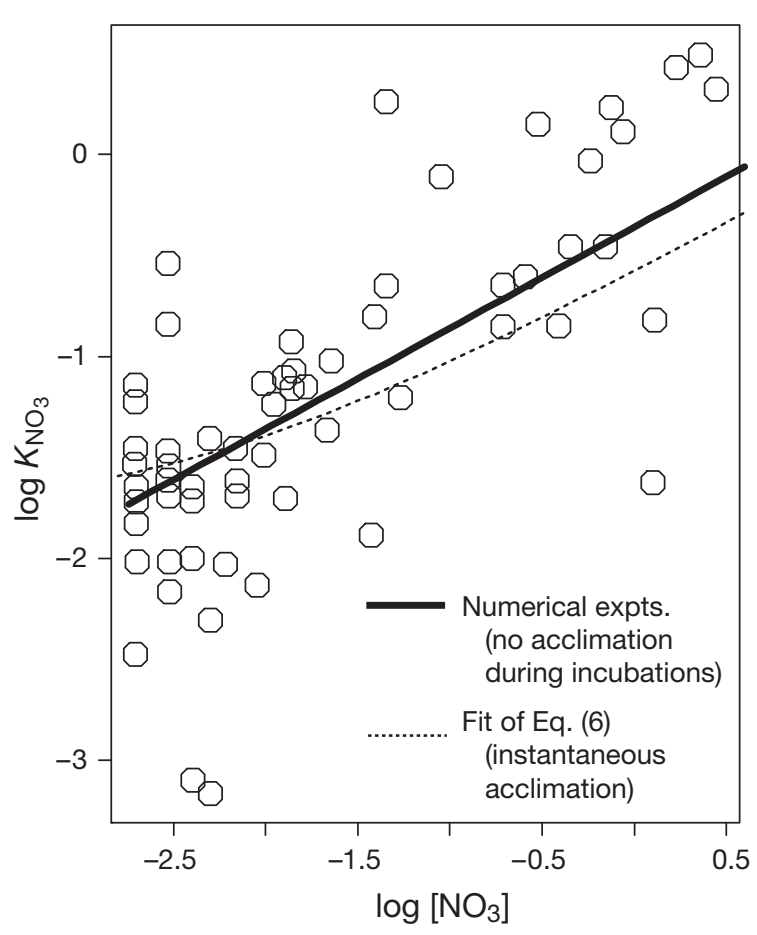

Fig. 3. Data (O) compiled from Harrison et al.(1996) and McCarthy et al. (1999) for $K_{\mathrm{NO}_{3}}$ and $\left[\mathrm{NO}_{3}\right]$ (both in $\mu \mathrm{mol} \mathrm{N}{ }^{-1}$ ) and results (lines) of idealized numerical simulations of the experiments to determine $K_{\mathrm{NO}_{3}}$ as described in Harrison et al. (1996). Simulations assumed that phytoplankton obeyed OU kinetics, sampled the predicted curve of uptake rate versus $\left[\mathrm{NO}_{3}\right]$ to generate 'data', and fit to this the MM equation to obtain values of $K_{\mathrm{NO}_{3}}$. We assumed $A_{0, \mathrm{NO}_{3}}=11 \mu_{\mathrm{mol}^{-1}} \mathrm{cell}^{-1}$ $\mathrm{d}^{-1}$ and $V_{0, \mathrm{NO}_{3}}=0.19 \mathrm{cell}^{-1} \mathrm{~d}^{-1}$, based on the ratio estimated from the fit with $b=0.5$, . (-): Simulations assuming that the phytoplankton were acclimated to the ambient nutrient concentration but did not have time to acclimate to the nutrient additions. (--.---): best-fit from a non-linear regression of the long-term approximation for $K_{\mathrm{s}}^{\text {app }}$ (Eq. 6): $\log K_{\mathrm{NO}_{3}}=\log$ $\left.\left(0.016[ \pm 0.003]+2\{0.016[ \pm 0.003])\left[\mathrm{NO}_{3}\right]\right\}^{0.5}\right),\left(\mathrm{r}^{2}=0.48, \mathrm{n}=61\right.$, $\left.t=7.70, \mathrm{p}<10^{-9}\right)$. Values in brackets are standard errors of fitted parameters

between $1 / T$ and $\left[\mathrm{NO}_{3}\right]$. A multiple regression including both terms yields: $\log K_{\mathrm{NO}_{3}}=-6.01[ \pm 8.37]+1600$ $[ \pm 2400] / T+0.427[ \pm 0.207] \log \left[\mathrm{NO}_{3}\right]\left(\mathrm{r}^{2}=0.656, \mathrm{n}=13\right.$, $F=11.5, \mathrm{p}<0.0017$; terms in brackets are standard errors for estimated values), for $K_{\mathrm{NO}_{3}}$ and $\left[\mathrm{NO}_{3}\right]$ in $\mu \mathrm{g}$ $\mathrm{l}^{-1}$ and $T$ in $\mathrm{K}$. The coefficient for $\log \left[\mathrm{NO}_{3}\right]$ was significantly different $(\alpha=0.1)$ from $0(p<0.062)$, but that for $1 / T$ was not $(\mathrm{p}<0.521)$. Adding $1 / T$ to the regression did not significantly improve the fitted values of log$K_{\mathrm{NO}_{3}}$ compared to the regression versus $\log \left[\mathrm{NO}_{3}\right]$ only (ANOVA: $F=0.438, \mathrm{p}<0.521$ ). Conversely, adding $\log \left[\mathrm{NO}_{3}\right]$ to the regression did significantly improve the fit, compared to the regression versus $1 / T$ only (ANOVA: $F=4.23, \mathrm{p}=0.062$ ).

The trend of decreasing $K_{\mathrm{NO}_{3}}$ with increasing temperature observed in this field data is opposite to the 

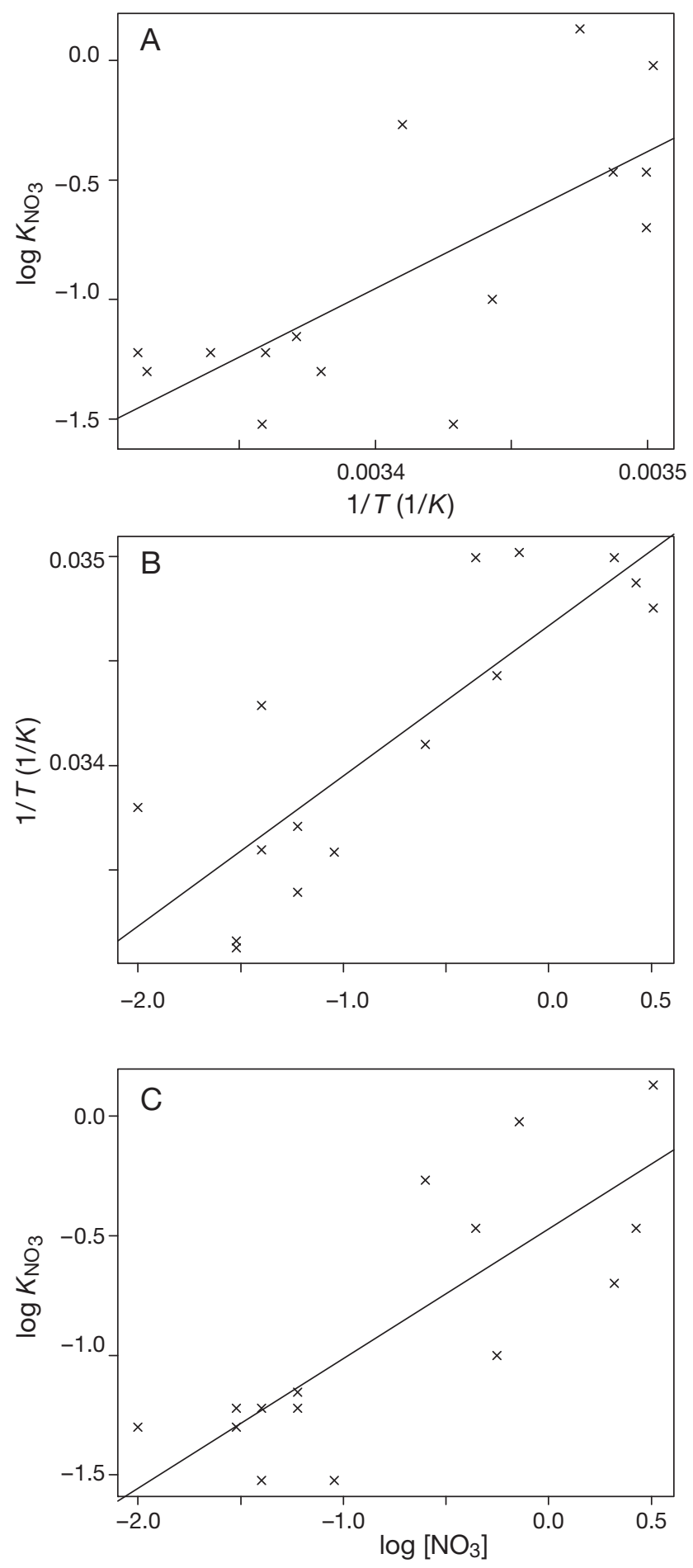

Fig. 4. Relationships between $\log K_{\mathrm{NO}_{3}}, \log \left[\mathrm{NO}_{3}\right]$ (both in $\mu \mathrm{g} \mathrm{N}$ $\mathrm{I}^{-1}$ ) and $1 / T$ ( $T$ in Kelvin) for the dataset of Kanda et al. (1985). Data $(x)$ and lines are linear regressions for each relationship. (A) $\log K_{\mathrm{NO}_{3}}$ versus $1 / T: \log K_{\mathrm{NO}_{3}}=-20.5[ \pm 5.07]+5740[ \pm 1480]$ $1 / T\left(\mathrm{r}^{2}=0.535, \mathrm{n}=13, F=15.0, \mathrm{p}<0.002\right)$, (B) $1 / T$ versus $\log \left[\mathrm{NO}_{3}\right]: 1 / T=3.47 \times 10^{-3}\left[ \pm 1.43 \times 10^{-5}\right]+7.19 \times 10^{-5}[ \pm 1.31 \times$ $\left.10^{-5}\right] \log \left[\mathrm{NO}_{3}\right]\left(\mathrm{r}^{2}=0.697, \mathrm{n}=13, F=29.9, \mathrm{p}<1.1 \times 10^{-4}\right),(\mathrm{C}) \log -$ $K_{\mathrm{NO}_{3}}$ versus $\log \left[\mathrm{NO}_{3}\right]: \log K_{\mathrm{NO}_{3}}=-0.471[ \pm 0.122]+0.542$ $[ \pm 0.112] \log \left[\mathrm{NO}_{3}\right]\left(\mathrm{r}^{2}=0.644, \mathrm{n}=13, F=23.5, \mathrm{p}<3.2 \times 10^{-4}\right)$. Values in brackets are standard errors of fitted parameters general increase observed in $K_{\mathrm{s}}$ with temperature for laboratory experiments using single-species cultures (Eppley et al. 1969, Dauta 1982). This strongly suggests that, for $K_{\mathrm{s}}$ the effect of nutrient concentration dominates that of temperature in field studies.

\section{Global simulations with the UVic-ESCM}

Compared to the standard UVic-ESCM run using MM kinetics (Schmittner et al. 2008), substantial regional differences emerge for the biogeochemical properties of the run using OU kinetics. Nutrient uptake and primary production are larger for OU than for $\mathrm{MM}$ whenever ambient nutrient concentrations fall below $0.7 \mu \mathrm{mol} \mathrm{l}^{-1}$, e.g. in the oligotrophic subtropical gyres. For higher nutrient concentrations, uptake and production are smaller in the OU run, which is the case predominantly at higher latitudes and in tropical upwelling regions ( ). Prior to the onset of the industrial revolution, zonally-averaged differences in simulated primary production between $\mathrm{OU}$ and $\mathrm{MM}$ kinetics reach $5 \mathrm{gC} \mathrm{m}^{-2} \mathrm{yr}^{-1}$ in the subtropics. Under global warming, stratification increases and the oligotrophic areas tend to expand. As a consequence, the zonallyaveraged primary production simulated by OU kinetics exceeds those of the MM run by up to $12 \mathrm{~g} \mathrm{C} \mathrm{m}^{-2}$ $\mathrm{yr}^{-1}$ in 2000 and $16 \mathrm{~g} \mathrm{C} \mathrm{m}^{-2} \mathrm{yr}^{-1}$ in 2100 ( ).

\section{DISCUSSION}

\section{Timescale for acclimation}

The time required for physiological acclimation of phytoplankton is the key to explaining why the MM equation generally fits the data from short-term experiments well (Harrison et al. 1989, Harrison et al. 1996, McCarthy et al. 1999), but cannot describe the longerterm response of phytoplankton in steady-state laboratory experiments over wide ranges of nutrient concentration (Droop 1974, Rhee 1974, Gotham \& Rhee 1981a,b, Smith \& Yamanaka 2007). In the former, the physiology for nutrient uptake is effectively frozen over the duration of the incubations, which yields a response consistent with the MM equation, albeit with different constants for phytoplankton pre-acclimated to different ambient nutrient concentrations. Over longer timescales, the acclimation assumed in OU kinetics produces a different response, which does agree with steady-state laboratory experiments over wide ranges of nutrient concentration (Smith \& Yamanaka 2007). Application of MM kinetics using 'constants' measured in short-term experiments will therefore not accurately reproduce the response of 

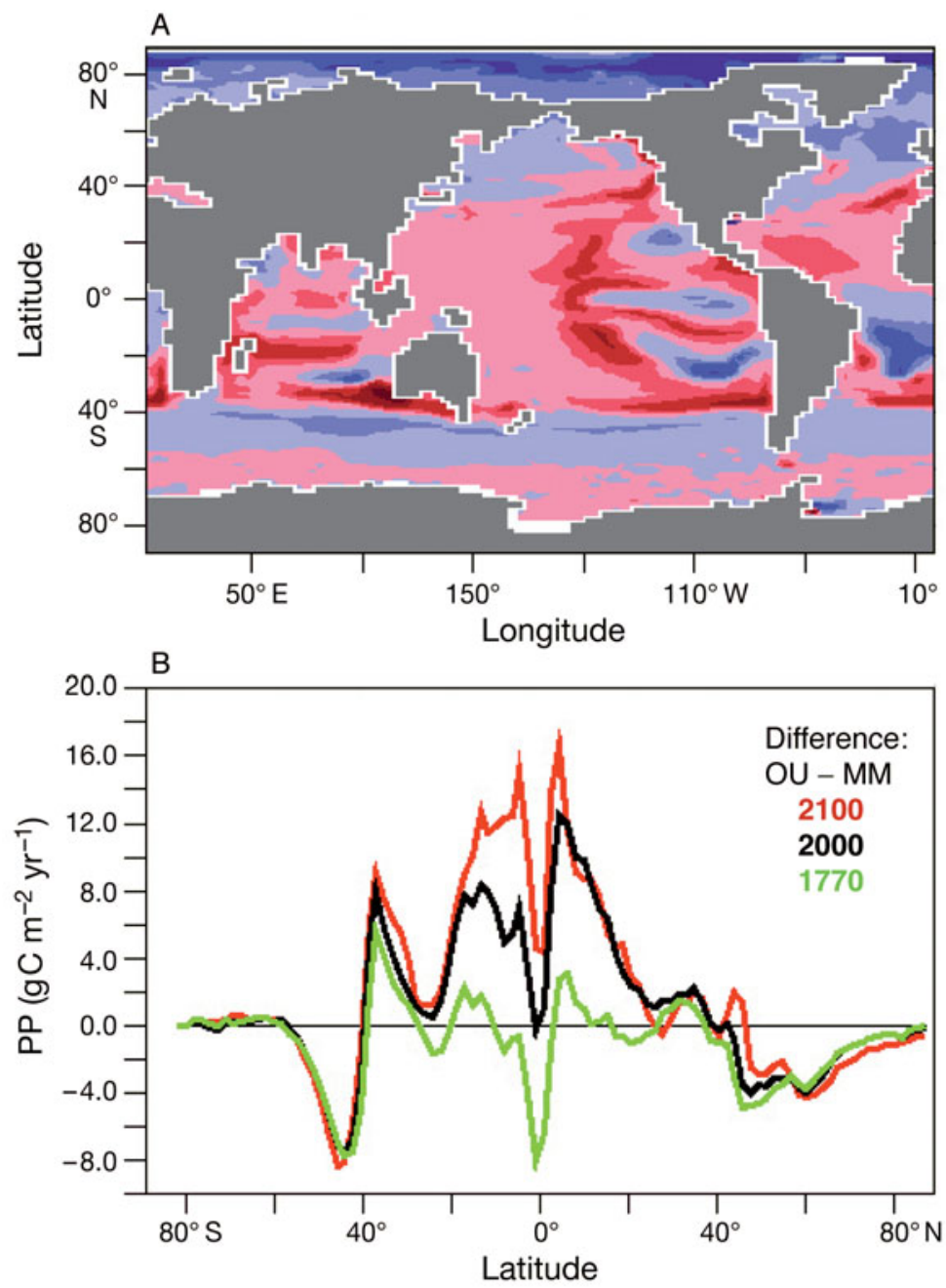

Fig. 5. Results from simulations with the UVic-ESCM (University of Victoria Earth System Climate Model) (Schmittner et al. 2005) over the period 1765 to 2100 forced by historical and business-as-usual greenhouse gas emissions (Schmittner et al. 2008), using either standard Michaelis-Menten (MM) or our optimal uptake (OU), Eq. (5), for phytoplankton nutrient uptake (Appendix A1). (A) Relative (\%) difference (OU - MM) in annual net primary production simulated for the year 2000. (B) Absolute difference (OU - MM) in zonally-averaged annual net primary production (PP) simulated for 1770 (green), 2000 (black) and 2100 (red)

phytoplankton to changes in nutrient supply in the ocean. Still, the data from these experiments contains valuable information, as they allowed us to estimate

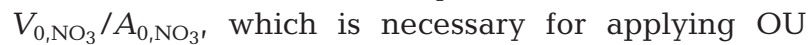
kinetics to the surface ocean.

The original studies with OU kinetics (Pahlow 2005, Smith \& Yamanaka 2007) assumed that the acclimation to nutrient concentration occurred instantaneously, and Pahlow (2005) obtained good agreement with data from experiments with measurements spaced at intervals on the order of $1 \mathrm{~d}$. Acclimation most likely requires at least several hours, based on the time required to equilibrate continuous cultures of phytoplankton (Harrison \& Morel 1986, Morel 1987) and on

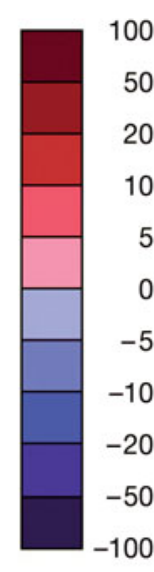

our results, but we do not know exactly how long. Most modern nutrient uptake experiments are performed over only 2 to $3 \mathrm{~h}$ (Harrison et al. 1989) to minimize variations in nutrient concentration during the incubations and are therefore not expected to measure the acclimated response of phytoplankton.

\section{Assemblages vs. single species}

We do not know why the OU equation, which represents the response of a single species, agrees with the response of the natural assemblages of phytoplankton in seawater. However, there are plausible reasons for this. Fits of models using OU kinetics with data from single-species culture experiments have yielded different values of $A_{0, S}$ and $V_{0, S}$ for each species (Pahlow 2005, Smith \& Yamanaka 2007), which reflect intrinsic physiological differences. Still, whatever such differences exist among the various phytoplankton that dominate at different nitrate concentrations, the ratio $V_{0, \mathrm{NO}_{3}} / A_{0, \mathrm{NO}_{3}}$ is apparently not a function of the ambient nitrate concentration because Eq. (10) fits the data with constant a according to Eq. (11). This is plausible, because the potential maximum affinities and potential maximum uptake rates depend, respectively, on the potential maximum numbers of uptake sites and internal enzymes per cell, both of which would be expected to increase with cell size. Maximum uptake rate (per cell) of a species tends to increase with both cell volume and minimum cell quota (content) of $\mathrm{N}$ (Litchman et al. 2007). Thus, even though cell size of the dominant phytoplankton tends to increase with ambient nutrient concentration, this ratio might not vary much as a function of ambient nutrient concentration.

Even if the species dominating in different environments have intrinsic differences in $V_{0, \mathrm{NO}_{3}} / A_{0, \mathrm{NO}_{3}}$, we can still expect the relationship observed between $K_{\mathrm{NO}_{3}}$ and nitrate concentration, as long as this ratio is not systematically determined by the nitrate concentration. There are several reasons to expect variability in observed nutrient uptake response. Even for a single species, we would not expect to explain all variations 
in $K_{\mathrm{NO}_{3}}$ in terms of nutrient concentration, because uptake response also varies as a function of temperature (Eppley et al. 1969, Eppley 1972, Dauta1982) and light (Armstrong 1999). Also, we would expect phytoplankton in the ocean to be acclimated to differing degrees to the ambient nutrient concentration at any given time and place, because of natural fluctuations in nutrient supply.

Furthermore, the same physiological trade-off that is key to the acclimation assumed in OU kinetics would also be expected to apply to the evolution of different species. Indeed, in terms of MM uptake parameters, Litchman et al. (2007) found a positive correlation between maximum uptake rate (per cell) and halfsaturation constant for nitrate uptake in a compilation of data for various species representing major functional types. The central trade-off in OU kinetics, reflected in the negative relationship between $V_{\max }$ and $A_{s}$ also results in a positive relationship between maximum uptake rate and apparent half-saturation constant, in qualitative agreement with the observed trend among species.

\section{Implications for predictability}

With respect to the variations in uptake response across oceanic regions, there is an important conceptual difference between the traditional interpretation in terms of MM kinetics and our interpretation in terms of OU kinetics. According to the former, the pattern is mostly determined by intrinsic differences between the species that dominate under different conditions, whereas according to the latter it is mostly determined by the fact that all phytoplankton acclimate to nutrient concentration in the same way, subject to the same physiological trade-off. The former implies low predictability, because those intrinsic physiological differences between dominant species cannot be predicted. In contrast, the latter implies that it should be possible to predict at least the response to changing nutrient concentrations, because all phytoplankton acclimate (or evolve) subject to the same physiological trade-off.

Currently, nearly all large-scale marine ecosystem models apply the $\mathrm{MM}$ equation with constant $K_{\mathrm{s}}$ to describe uptake (or growth) rates of phytoplankton as a function of nutrient concentrations, and most such models include $\mathrm{N}$ as either the only or one of a few limiting nutrients (Fasham et al. 1993, Oschlies et al. 2000, LeQuere et al. 2005, Gruber et al. 2006, Hood et al. 2006, Hashioka \& Yamanaka 2007). Our results show that OU kinetics is a better description of the observed uptake response over wide areas of the ocean, at least for the key nutrient nitrate. The assumption of instantaneous acclimation cannot be rigorously correct be- cause physiological changes must require some time, and the assumption of constant parameter values in OU kinetics may not be correct either. However, based on our results, these assumptions will introduce much less error than the application of MM kinetics with constant $K_{\mathrm{s}}$, which is the current standard in marine ecosystem modeling.

Even high spatial-resolution, large-scale marine ecosystem models have not been able to reproduce the observed contrast in phytoplankton biomass and production between eutrophic and oligotrophic regions (Oschlies et al. 2000, Gruber et al. 2006). To remedy this, it has been suggested to add more functional types or processes to the models, which would make them more complex. At least with respect to variations along nutrient gradients, a simpler alternative is to include the effects of physiological acclimation in the existing functional types by incorporating OU kinetics, rather than adding more compartments to already complex models. Because of the acclimation to ambient nutrient concentrations, OU kinetics should provide a more realistic description of the contrast between nutrient-rich and nutrient-poor regions of the ocean.

For predictive modeling of marine ecosystems and biogeochemical cycles, this acclimation is critical because changes in ocean circulation and mixing (e.g. as a result of global warming or climate oscillations) will alter the rates of nutrient supply to the surface ocean. For example, the nutrient-poor subtropical gyres have expanded over the past decade as their average surface temperatures have increased (Polovina et al. 2008). Application of MM kinetics with empirical relationships to describe changes in $K_{\mathrm{NO}_{3}}$ will not accurately describe even the past response of phytoplankton unless the variations in $V_{\max }$ are also addressed, which would be difficult because of the wide variation in patterns of values of $V_{\max }$ fit to the MM equation. OU kinetics thus presents a superior alternative to the $\mathrm{MM}$ equation for modeling nutrient uptake kinetics in the ocean.

Our results with the UVic-ESCM illustrate that using the new OU kinetics can substantially alter regional and temporal variations in simulated ecosystem dynamics. When calibrating such models with observations that cover a large range of environmental conditions, it is essential to avoid fitting incorrect dynamics to the data. Our results suggest that nutrient uptake kinetics can significantly affect spatial and temporal patterns of biological production and therefore has to be accounted for carefully.

Acknowledgements. We thank E. Wada for helpful discussions, S. Manabe for valuable suggestions, and the anonymous reviewers for thorough, constructive reviews. 


\section{LITERATURE CITED}

Aksnes DL, Egge JK (1991) A theoretical model for nutrient uptake in phytoplankton. Mar Ecol Prog Ser 70:65-72

Armstrong RA (1999) An optimization-based model of ironlight-ammonium colimitation of nitrate uptake. Limnol Oceanogr 44:1436-1446

Caperon J (1968) Population growth response of Iscochrysis galbana to nitrate variation at limiting concentrations. Ecology 49:866-872

Collos Y (1980) Transient situations in nitrate assimilation by marine diatoms. 1. Changes in uptake parameters during nitrogen starvation. Limnol Oceanogr 25:1075-1081

> Collos Y, Vaquer A, Souchu P (2005) Acclimation of nitrate uptake by phytoplankton to high substrate levels. J Phycol 41:466-478

Dauta A (1982) Conditions de développement du phytoplancton. Étude comparative du comportement de huit espès en culture. 2. Role des nutriments: Assimilation et stockage intracellulaire. Ann Limnol 18:263-292 (in French)

> Dortch Q, Thompson PA, Harrison PJ (1991) Variability in nitrate uptake kinetics in Thalassiosira pseudonana (Bacillariophyceae). J Phycol 27:35-39

Droop MR (1968) Vitamin B12 and marine ecology. 4. The kinetics of uptake, growth and inhibition of Monochrysis lutheri. J Mar Biol Assoc UK 48:689-733

Droop MR (1974) The nutrient status of algal cells in continuous culture. J Mar Biol Assoc UK 54:825-855

Duce RA, LaRoche J, Altieri K, Arrigo KR and others (2008) Impacts of atmospheric anthropogenic nitrogen on the open ocean. Science 320:893-897

Dugdale RC (1967) Nutrient limitation in the sea: dynamics, identification, and significance. Limnol Oceanogr 12: 685-695

Dugdale RC, Goering JJ (1967) Uptake of new and regenerated forms of nitrogen in primary productivity. Limnol Oceanogr 12:197-206

Eppley RW (1972). Temperature and phytoplankton growth in the sea. Fish Bull (Wash D C) 70:1063-1085

Eppley RW, Rogers JN, McCarthy JJ (1969) Half-saturation constants for uptake of nitrate and ammonium by marine phytoplankton. Limnol Oceanogr 14:912-920

Faraway JJ (2005) Linear models with R. Chapman Hall/CRC Press, Boca Raton, LA

Fasham MJR, Sarmiento JL, Slater RD, Ducklow HW, Williams R (1993) Ecosystem behaviour at Bermuda station 'S' and ocean weather station 'India': a general circulation model and observational analysis. Glob Biogeochem Cycles 7:379-415

Goldman JC, Carpenter EJ (1974) A kinetic approach to the effect of temperature on algal growth. Limnol Oceanogr 19:756-766

Gotham IJ, Rhee GY (1981a) Comparative kinetic studies of nitrate-limited growth and nitrate uptake in phytoplankton in continuous culture. J Phycol 17:309-314

Gotham IJ, Rhee GY (1981b) Comparative kinetic studies of phosphate-limited growth and phosphate uptake in phytoplankton in continuous culture. J Phycol 17: 257-265

Gruber N, Frenzel H, Doney S, Marchesiello P, McWilliams JC, Moisan JR, Oram J, Plattner GK, Stolzenbach K (2006) Eddy-resolving simulation of plankton ecosystem dynamics in the California current system. Deep-Sea Res I 53: $1483-1516$

Harrison G, Morel FMM (1986) Response of the marine diatom Thalassiosira weissflogii to iron stress. Limnol Oceanogr 31:989-997
Harrison PJ, Parslow JS, Conway HL (1989) Determination of nutrient uptake kinetic parameters: a comparison of methods. Mar Ecol Prog Ser 52:301-312

Harrison WG, Harris LR, Irwin DB (1996) The kinetics of nitrogen utilization in the oceanic mixed layer: nitrate and ammonium interactions at nanomolar concentrations. Limnol Oceanogr 41:16-32.

Hashioka T, Yamanaka Y (2007) Seasonal and regional variations of phytoplankton groups by top-down and bottomup controls obtained by a 3D ecosystem model. Ecol Modell 202:68-80

Healey FP (1980) Slope of the Monod equation as an indicator of advantage in nutrient competion. Microb Ecol 5: 281-286

Hood RR, Laws EA, Armstrong RA, Bates NR and others (2006) Pelagic functional group modeling: Progress and prospects. Deep-Sea Res. II 53:459-512

Kanda J, Saino T, Hattori A (1985) Nitrogen uptake by natural populations of phytoplankton and primary production in the pacific ocean: regional variability of uptake capacity. Limnol Oceanogr 30:987-999

Klausmeier CA, Litchman E, Levin SA (2004) Phytoplankton growth and stoichiometry under multiple nutrient limitation. Limnol Oceanogr 49:1463-1470

LeQuere C, Harrison SP, Prentice IC, Buitenhuis ET and others (2005) Ecosystem dynamics based on plankton functional types for global ocean biogeochemistry models. Glob Change Biol 11:2016-2040

Litchman E, Klausmeier CA, Schofield OM, Falkowski PG (2007) The role of functional traits and trade-offs in structuring phytoplankton communities: scaling from cellular to ecosystem level. Ecol Lett 10(12):1170-1181

McCarthy JJ, Garside C, Nevins JL (1999) Nitrogen dynamics during the Arabian Sea Northeast Monsoon. Deep-Sea Res II 46:1623-1664

Morel FMM (1987) Kinetics of nutrient uptake and growth in phytoplankton. J Phycol 23:137-150

Oschlies A, Koeve W, Garcon V (2000) An eddy-permitting coupled physical-biological model of the north atlantic 2 . ecosystem dynamics and comparison with satellite and jgofs local studies data. Global Biogeochem Cycles 14: 499-523

Pahlow M (2005) Linking chlorophyll-nutrient dynamics to the Redfield N:C ratio with a model of optimal phytoplankton growth. Mar Ecol Prog Ser 287:33-43

Parsons TR, Takahashi M, Hargrave B (1984) Biological oceanographic processes. Pergamon Press, Oxford, NY

> Pedersen MF (1994) Transient ammonium uptake in the macroalga ulva lactuca (chlorophyta): nature, regulation, and the consequences for choice of measuring technique. J Phycol 30:980-986

> Polovina JJ, Howell EA, Abecassis M (2008) Ocean's least productive waters are expanding. Geophys Res Lett 35, L03618, doi:10.1029/2007GL031745

> Raimbault P, Gentilhomme V (1990) Short- and long-term responses of the marine diatom phaeodactylum tricornutum to spike additions of nitrate at nanomolar levels. J Exp Mar Biol Ecol 135:161-176

Rhee GY (1974) Phosphate uptake under nitrate limitation by Scenedesmus sp. and its ecological implications. J Phycol 10:470-475

Schmittner A, Oschlies A, Giraud X, Eby M, Simmons HL (2005) A global model of the marine ecosystem for longterm simulations: sensitivity to ocean mixing, buoyancy forcing, particle sinking, and dissolved organic matter cycling. Global Biogeochem Cycles 19, GB3004, doi: 10.1029/2004GB002283 
Schmittner A, Oschlies A, Mathews HD, Galbraith ED (2008) Future changes in climate, ocean circulation, ecosystems, and biogeochemical cycling simulated for abusiness-asusual $\mathrm{CO}_{2}$ emission scenario until year $4000 \mathrm{AD}$. Global Biogeochem Cycles 22, GB1013, doi:10.1029/2007GB002953

Shiomoto A, Sasaki K, Shimoda T, Matsumura S (1994) Kinetics of nitrate and ammonium uptake by the natural populations of marine phytoplankton in the surface water of the oyashi region during spring and summer. J Oceanogr 50:515-529

Smith SL, Yamanaka Y (2007) Optimization-based model of multinutrient uptake kinetics. Limnol Oceanogr 52: $1545-1558$

Appendix 1. Optimal $\mathrm{N}$ and P uptake with the UVic model

The University of Victoria Earth System Climate Model (UVic-ESCM) (Schmittner et al. 2005, 2008) describes primary production as a function of light, nitrate and phosphate and also allows for $\mathrm{N}_{2}$ fixation by diazotrophs. We apply the SPONGE model of optimal uptake to multiple limiting nutrients (Smith \& Yamanaka 2007) to implement OU kinetics for nitrate and phosphate co-limitation, and implement the single-nutrient OU (Eq. 5 in the main text) to deal with phosphate limitation of diazotrophs. Non-diazotrophic phytoplankton growth rate $\left(J_{\mathrm{O}}\right)$ is formulated as the minimum of potential light, $\mathrm{N}$, and $\mathrm{P}$ limited growth rates in the UViC-ESCM:

$$
J_{\mathrm{O}}=\min \left(J_{\mathrm{I}}, J_{\max , \mathrm{O}} u^{\mathrm{N}}, J_{\max , \mathrm{O}} u^{\mathrm{P}}\right)
$$

where $J_{\mathrm{I}}$ and $J_{\max , \mathrm{O}}$ are the potential light-limited and maximal growth rates, respectively, and $u^{\mathrm{N}}$ and $u^{\mathrm{P}}$ describe potential limitation by $\mathrm{N}$ and $\mathrm{P}$. The standard UVic-ESCM uses MM kinetics to calculate nutrient uptake:

$$
\begin{gathered}
v^{\mathrm{N}}=J_{\mathrm{max}, \mathrm{O}} P_{\mathrm{O}} u^{\mathrm{N}} \quad v^{\mathrm{P}}=J_{\mathrm{max}, \mathrm{O}} \frac{P_{\mathrm{O}}}{R_{\mathrm{NP}}} u^{\mathrm{P}} \\
u^{\mathrm{N}}=u_{\mathrm{MM}}^{\mathrm{N}}=\frac{\left[\mathrm{NO}_{3}\right]}{\left[\mathrm{NO}_{3}\right]+K_{\mathrm{NO}_{3}}} \quad u^{\mathrm{P}}=u_{\mathrm{MM}}^{\mathrm{P}}=\frac{\left[\mathrm{PO}_{4}\right]}{\left[\mathrm{PO}_{4}\right]+K_{\mathrm{PO}_{4}}} \\
K_{\mathrm{PO}_{4}}=\frac{K_{\mathrm{NO}_{3}}}{R_{\mathrm{NP}}}
\end{gathered}
$$

where $P_{\mathrm{O}}$ is non-diazotrophic phytoplankton N concentration and $R_{\mathrm{NP}}=16$ is the Redfield N:P ratio. OU kinetics is implemented by replacing the MM nutrient limitation terms, $u_{\mathrm{MM}}^{\mathrm{N}}$ and $u_{\mathrm{MM}}^{\mathrm{P}}$, with their OU counterparts, $u_{\mathrm{OU}}^{\mathrm{N}}$ and $u_{\mathrm{OU}}^{\mathrm{P}}$ :

$$
\begin{aligned}
& u^{\mathrm{N}}=u_{\mathrm{OU}}^{\mathrm{N}}=\frac{\left[\mathrm{NO}_{3}\right]}{\frac{\left[\mathrm{NO}_{3}\right]}{1-f_{A}}+\frac{V_{0, \mathrm{NO}_{3}}}{f_{A} A_{0, \mathrm{NO}_{3}}}} \quad V_{0, \mathrm{NO}_{3}}=f J_{\mathrm{max}, \mathrm{O}} P_{\mathrm{O}} \\
& u^{\mathrm{P}}=u_{\mathrm{OU}}^{\mathrm{P}}=\frac{\left[\mathrm{PO}_{4}\right]}{\frac{\left[\mathrm{PO}_{4}\right]}{1-f_{A}}+\frac{V_{0, \mathrm{PO}_{4}}}{f_{A} A_{0, \mathrm{PO}_{4}}}} \quad V_{0, \mathrm{PO}_{4}}=f J_{\max , \mathrm{O}} \frac{P_{\mathrm{O}}}{R_{\mathrm{NP}}}
\end{aligned}
$$

where $f$ is a scale factor used here to align OU and MM kinetics at $\left[\mathrm{NO}_{3}\right]=K_{\mathrm{NO}_{3}}\left(\right.$ or $\left.\left[\mathrm{PO}_{4}\right]=K_{\mathrm{PO}_{4}}\right)$ (see below). The SPONGE model (Smith \& Yamanaka 2007) stipulates that acclimation of $f_{A}$ occurs with respect to the limiting nutrient only, which gives, in the context of an external growth function:

$$
f_{A}=\max \left[\left(1+\sqrt{\frac{A_{0, \mathrm{NO}_{3}\left[\mathrm{NO}_{3}\right]}^{V_{0, \mathrm{NO}_{3}}}}{{ }^{\prime}}}\right)^{-1},\left(1+\sqrt{\frac{A_{0, \mathrm{PO}_{4}}\left[\mathrm{PO}_{4}\right]}{V_{0, \mathrm{PO}_{4}}}}\right)^{-1}\right]
$$

Note that $f_{A}$ denotes allocation of $\mathrm{N}$ within the uptake apparatus, even when phosphate is limiting.

The ratios $V_{0, \mathrm{NO}_{3}} / A_{0, \mathrm{NO}_{3}}$ and $V_{0, \mathrm{PO}_{4}} / A_{0, \mathrm{PO}_{4}}$ in Eqs. (A4)-(A6) are determined from the fit of the short-term approximation to data (Eq. 8 in the main text):

$$
\begin{gathered}
K_{\mathrm{NO}_{3}}^{\mathrm{app}}=\sqrt{\frac{V_{0, \mathrm{NO}_{3}}}{A_{0, \mathrm{NO}_{3}}}\left[\mathrm{NO}_{3}\right]} \Leftrightarrow \\
\log K_{\mathrm{NO}_{3}}^{\mathrm{app}}=0.5 \log \frac{V_{0, \mathrm{NO}_{3}}}{A_{0, \mathrm{NO}_{3}}}+0.5 \log \left[\mathrm{NO}_{3}\right] \\
\log K_{\mathrm{NO}_{3}}^{\mathrm{app}}=-0.364+0.5 \log \left[\mathrm{NO}_{3}\right] \Rightarrow \\
\frac{V_{0, \mathrm{NO}_{3}}}{A_{0, \mathrm{NO}_{3}}}=10^{2 \cdot(-0.364)}=0.187 \\
\frac{V_{0, \mathrm{PO}_{4}}}{A_{0, \mathrm{PO}_{4}}}=\frac{V_{0, \mathrm{NO}_{3}}}{A_{0, \mathrm{NO}_{3}} R_{\mathrm{NP}}}
\end{gathered}
$$

where concentrations of $\mathrm{NO}_{3}$ and $\mathrm{PO}_{4}$ and the ratios $V_{0} / A_{0}$ are in units of $\mu \mathrm{mol} l^{-1}$. Matching $V_{\mathrm{N}}^{\mathrm{OU}}$ and $V_{\mathrm{N}}$ at $\left[\mathrm{NO}_{3}\right]=K_{\mathrm{N}}$ yields, using Eq. (A4):

$$
\begin{aligned}
& \frac{f J_{\max }}{\left(\sqrt{\frac{V_{0, \mathrm{NO}_{3}}}{A_{0, \mathrm{NO}_{3}} K_{\mathrm{NO}_{3}}}}+1\right)^{2}}=0.5 J_{\max } \Leftrightarrow \\
& f=0.5\left(\sqrt{\frac{V_{0, \mathrm{NO}_{3}}}{A_{0, \mathrm{NO}_{3}} K_{\mathrm{NO}_{3}}}}+1\right)^{2}=1.15
\end{aligned}
$$

which is the same for $\mathrm{NO}_{3}$ and $\mathrm{PO}_{4}$.

Diazotrophs have lower affinity in the UVic-ESCM $J_{\text {max }, \mathrm{D}}<J_{\max , \mathrm{O}}, K_{\mathrm{D}}=K$ ):

$$
\begin{gathered}
V_{0, \mathrm{D}}=V_{0} \frac{J_{\max , \mathrm{D}}}{J_{\max , \mathrm{O}}}, \quad A_{0, \mathrm{D}}=A_{0} \frac{J_{\text {max }, \mathrm{D}}}{J_{\text {max }, \mathrm{O}}} \Leftrightarrow \\
\frac{V_{0, \mathrm{D}}}{A_{0, \mathrm{D}}}=\frac{V_{0}}{A_{0}} \Rightarrow f_{\mathrm{D}}=f=1.15
\end{gathered}
$$

where the subscript $\mathrm{D}$ indicates quantities applied to diazotroph growth. Diazotrophs can use $\mathrm{N}_{2}$ if nitrate is more limiting than phosphate. Thus, $f_{A, \mathrm{D}}$ acclimates always to $\mathrm{PO}_{4}$ :

$$
f_{A, \mathrm{D}}=\frac{1}{1+\sqrt{\frac{A_{0, \mathrm{PO}_{4}, \mathrm{D}}\left[\mathrm{PO}_{4}\right]}{V_{0, \mathrm{PO}_{4}, \mathrm{D}}}}}=\frac{1}{1+\sqrt{\frac{A_{0, \mathrm{PO}_{4}}\left[\mathrm{PO}_{4}\right]}{V_{0, \mathrm{PO}_{4}}}}}
$$

